\title{
ENCONTROS, DERIVAS E INTERCESSORES EM UM ACOMPANHAMENTO TERAPÊUTICO
}

\author{
MEETINGS, DERIVATIVES AND INTERCESSORS IN THERAPEUTIC FOLLOW UP \\ ENCUENTROS, DERIVAS E INTERCESORES EN UN ACOMPAÑAMIENTO TERAPÉUTICO
}

\author{
Dami Silva* \\ Caio César Souza Camargo Próchno* \\ Ricardo Wagner Machado Silveira ${ }^{* *}$
}

\begin{abstract}
RESUMO
Este artigo é parte de uma pesquisa de mestrado motivada por um acompanhamento terapêutico e por uma questão que surgiu em meio aos encontros: o que se passa entre acompanhado e acompanhante? Tradicionalmente, essa prática é reconhecida por utilizar-se das ruas e saídas, como modo de não ficar restrita ao ambiente físico das instituições ou ao setting tradicional da clínica. Neste trabalho, tendo como referências o pensamento de Deleuze e Guattari, utilizamos a cartografia como método de pesquisa-intervenção, do qual destacaremos aqui alguns fragmentos de relatos e, principalmente, seus enredamentos conceituais, mostrando como ambos se compuseram nos (e partir dos) encontros nos quais acompanhado e acompanhante teceram juntos uma rede de relações contagiando o cotidiano, a vizinhança, o comércio, a informática, os fazeres e os saberes a respeito da clínica. São experimentações, agenciamentos, acontecimentos e derivas que se passam entre acompanhado e acompanhante em intensidades que os arrastam, produzindo outros modos de ver, pensar, sentir e estar no mundo.
\end{abstract}

Palavras-chave: Acompanhamento terapêutico. Clínica. Cartografia.

\section{ABSTRACT}

This article is part of a master research motivated by a therapeutic follow up and by one question that emerged during the meetings, which is: what

\footnotetext{
Texto recebido em 5 de novembro de 2013 e aprovado para publicação em 16 de outubro de 2014.

Mestrando em Psicologia Aplicada pelo Programa de Pós-Graduação em Psicologia da Universidade Federal de Uberlândia (UFU), Eixo da Intersubjetividade - área Psicanálise, Psicopatologia e Cultura; psicólogo clínico pela UFU; bacharel em Psicologia pela UFU. E-mail: dami_silva@hotmail.com.

* Professor doutor do Programa de Pós-Graduação do Instituto de Psicologia da UFU. Suas duas grandes linhas de pesquisa são "Corpo e Cultura" e "Filosofia do Corpo", as quais contêm projetos de pesquisa, tais como "Corpo e Consumo", "Análise Institucional do Corpo", "Corpo do Ator", "Nietzsche, Corpo e Potência". Terminou recentemente seu pós-doutorado na Universidade de Leipzig, Alemanha, com o tema da "loucura no corpo de Nietzsche", tendo sido orientado pelo prof. dr. Christoph Türcke.E-mail: c.prochno@uol.com.br.

${ }^{* * *}$ Docente no Instituto de Psicologia da UFU. Experiência em pesquisas e práticas relacionadas com a Clínica Antimanicomial e Programas de Atendimento Comunitário de Saúde Mental com ênfase em acompanhamento terapêutico, redução de danos, supervisão clínico-institucional em CAPSad, atuação do psicólogo no PSF, pesquisas epidemiológicas de saúde mental na saúde coletiva e educação permanente em saúde. E-mail: ricardowagner@ipsi.ufu.br.
} 
passes between accompanied and accompanying person? Traditionally, this practice is known as a clinical that uses street and walks, in order to not be restricted to the physical space of the institutions or to the traditional clinical setting. In this work, taking as references the thoughts of Deleuze and Guattari, we used the cartography as a method of intervention research. We will highlight some fragments of reports, mainly, their conceptual entanglements, showing how both served as intercessors and composed meetings, in which accompanied and accompanying wove together a range of relationships covering the daily life, for example with neighbors, commerce, family, computer, tasks and knowledge about the clinic. These are the trials, assemblages, events and drifts that pass between accompanying and accompanied at intensities that produce other ways of seeing, thinking, feeling and being in the world.

Keywords: Therapeutic accompaniment. Clinic. Cartography.

\section{RESUMEN}

Este artículo es parte de una investigación de maestría motivada por un acompañamiento terapéutico y por una cuestión que surgió en medio de los encuentros: ¿qué pasa entre el acompañado y acompañante? Tradicionalmente, esta práctica es reconocida por el uso de las calles y salidas, para que no se limite al ambiente físico de las instituciones o al setting tradicional de la clínica. En este trabajo, tomando como referencia el pensamiento de Deleuze e Guattari, utilizamos la cartografía como método de investigación-intervención, del cual vamos a destacar algunos fragmentos de los relatos y sobre todo sus enredos conceptuales, que muestran cómo ambos fueran hechos en (y desde) los encuentros durante los cuales acompañante y acompañado tejieron juntos una red de relaciones que implican la vida cotidiana, los vecinos, el comercio, la informática, los quehaceres y conocimientos acerca de la clínica. Son ensayos, gestiones, eventos y derivas que pasan entre acompañado y acompañante en intensidades que los arrastran, produciendo otras formas de ver, pensar, sentir y estar en el mundo.

Palabras clave: Acompañamiento terapéutico. Clínica. Cartografía.

\section{INTRODUÇÃO}

\footnotetext{
Este artigo é parte de uma dissertação de mestrado em que cartografamos os encontros, os conceitos, as experimentaçóes e suas composiçóes em um acompanhamento terapêutico motivados por uma pergunta: o que se passa entre acompanhado e acompanhante?
} 
Tradicionalmente, o acompanhamento terapêutico pode ser considerado como sair ou estar na rua com o paciente, acompanhando e compartilhando experiências e vivências; e o acompanhado, como aquele que costuma estar afastado do contato com o social ou que foi retirado (ou se retirou) dos espaços de circulação. Neste trabalho, fizemos uma aproximação do acompanhamento terapêutico e o pensamento de Deleuze e Guattari. Para isso, utilizamos a cartografia - formulação de Deleuze e Guattari (1995) - como um de nossos intercessores. Os intercessores são importantes para a criação e podem ser pessoas, conceitos, coisas, plantas, até animais, também podem ser fictícios, reais, animados ou inanimados. Os intercessores servem para pensar o processo, o movimento, as transformações (Deleuze, 2010).

Passos, Kastrup e Escóssia (2009) apontam que a cartografia como método privilegia germes potenciais para mudança e que a prática clínica é intervenção geradora de conhecimento. A cartografia se dirige não às formas, ao instituído, indivíduo ou social, mas ao coletivo como um plano de forças, ao instituinte, aos processos de subjetivação. Assim, interessa tudo aquilo que possa tornase dispositivo de intervenção, abrindo possibilidades de passagem, mudança, desvio e criação.

A cartografia é também considerada como um método de pesquisaintervenção, de modo que pesquisar e intervir não se diferenciam. Isso aponta para o fato de que conhecer e fazer não estão separados: o processo de pesquisar faz emergir o objeto, o sujeito e o conhecimento como efeito desse pesquisar; assim, não há saber dado a priori a respeito da realidade. O saber então emerge do fazer, colocando o trabalho referenciado por um fazer-saber, transformar para conhecer e não conhecer para transformar. Além disso, é um método que se coloca para ser experimentado e não aplicado, sendo então construído durante o próprio encontro (Passos, Kastrup \& Escóssia, 2009).

O acompanhado é Pedro (nome fictício), tem 33 anos, solteiro, com hipótese diagnóstica de transtornos mentais e comportamentais associado ao uso de múltiplas drogas, mas, segundo relatou, já estava há um ano e sete meses sem as usar. $\mathrm{O}$ acompanhamento terapêutico foi indicado porque Pedro não queria mais comparecer à instituição de saúde e, em casa, restringia-se a ficar no quarto. Embora reticente, o acompanhado aceitou a nossa proposta de fazer o acompanhamento terapêutico.

Nesse contexto, os encontros com Pedro, as saídas, os passeios ou mesmo em casa, assim como as supervisões em grupo, o próprio processo de pesquisar e os conceitos com os quais fizemos aproximações ressoaram na produção de um fazersaber sobre a clínica do acompanhamento terapêutico. Este artigo compreende 
alguns fragmentos desses encontros e como esses elementos se tornaram aliados na composição por aquilo que passa entre acompanhado e acompanhante.

\section{ENCONTROS E DERIVAS}

Nos primeiros encontros, diante de dúvidas sobre o que e como fazer, sugeri a Pedro fazer saídas pelo bairro, convite que ele, para nossa surpresa, prontamente aceitou. A aposta era que, por meio dos passeios e saídas, algo pudesse acontecer. Em uma das cenas que marcaram esse encontro, Pedro, de início, começou a caminhar rapidamente enquanto dizia que não precisava do Centro de Atenção Psicossocial - Álcool e Drogas (CAPS-ad). Nessa oportunidade, tentávamos acompanhá-lo, ouvi-lo, conversar e explicar sobre o acompanhamento, mas ele não mostrava atenção. Então mudamos de assunto e passamos a falar sobre a vizinhança. Pedro falou sobre vizinhos e sobre os bairros próximos. Quando chegamos no portão de sua casa, antes de entrarmos, perguntamos sobre como ele havia vindo para esta cidade. Nesse momento, antes de abrir o portão com a chave, como que tomado pela pergunta, Pedro parou o movimento que havia começado, acendeu um cigarro e se agachou. Agachamo-nos junto dele, e passamos a conversar então sobre a cidade pequena de onde ele tinha vindo, de roça e plantações de café, agachados tranquilamente na calçada.

Foi como se passássemos de uma pressa e velocidade da caminhada, na qual Pedro fazia questão de reafirmar que não precisava do CAPS-ad (muito menos do acompanhamento terapêutico, como nos pareceu), para uma parada, uma suspensão logo em seguida, uma calma e tranquilidade, em que Pedro parecia, de certo modo, dar alguma abertura à presença do acompanhante.

Logo depois, ele propôs que procurássemos uma loja de móveis, a fim de comprar uma mesa para o computador que havia ganhado. Hesitei por um momento em razão de que essa procura seria feita num bairro mais distante e estávamos apenas no primeiro encontro, mas aceitamos o convite, apostando em algo que pudesse acontecer, e fomos para essa procura. Acompanhamos Pedro. Atravessávamos de uma rua a outra, passando por vários quarteirões, enquanto ele dizia que a loja estaria adiante. Visto não encontrarmos nenhuma loja, dissemos a ele que poderíamos consultar uma lista telefônica para saber onde ficava tal loja e voltamos para casa.

No encontro seguinte, Pedro novamente se dispôs a sair, mas, como já havia ganhado uma mesa, sugerimos apenas caminharmos. Saímos. Pedro, sem muitas palavras, começou a fazer o mesmo trajeto do primeiro dia, tomando o caminho de volta para casa. Insistimos então para conhecermos outras partes do bairro 
e indicamos outros caminhos. Ele aceitou e, depois de alguns quarteirões, deliberadamente tomou a frente da caminhada e começou a procurar uma loja de material elétrico, a fim de comprar materiais para a instalação elétrica do computador que havia ganhado. Fizemos a compra juntos, cada um se encarregando de uma tarefa. Depois desse dia, com o computador funcionando, Pedro nos chamou para dentro de casa, no quarto, para apresentar o computador e, primeiramente, para o ajudarmos a sair de uma tela de boas-vindas. A partir daí, boa parte do acompanhamento terapêutico passou a ser nesse quarto, diante daquela máquina.

Entendendo o andar pelas ruas como uma intervenção, uma experimentação capaz de contagiar outros espaços e outras situações para além e aquém da rua, remetemos esses passeios à deriva, que, num primeiro momento, referia-se a passeios ou saídas pelas ruas sem uma finalidade ou um rumo pré-definido. Araújo (2006) relaciona a deriva a agenciamentos que vão do ambiente à subjetividade, assim como fala de uma circulação como experiência de desvio e deriva. Por sua vez, Rolnik (1997) fala de uma clínica nômade e da utilização de vários territórios pelos quais se circula. Já os situacionistas, ${ }^{1}$ de modo geral, falavam de deriva como participação nas cidades, com a ideia da colagem, da mistura contra o excesso de racionalidade e funcionalidade modernas. Por meio de suas intervenções, eles queriam possibilitar que as ruas fossem lugar de encontros e de transformação (Jacques, 2003).

Esses conceitos de deriva nos levaram a pensar que, tomando os vários elementos que apareciam nos encontros, seja a rua, o computador, as caminhadas, teorias e conceitos, inclusive tomando o próprio acompanhamento terapêutico para além de sua funcionalidade, poderíamos ampliar as possibilidades de criação. Nessa composição, os conceitos de força, agenciamento e acontecimento surgem como elementos aliados ou intercessores que, tomados em função dos encontros, ajudaram-nos a compor o próprio conceito de deriva que se destaca. O que nos interessa nos conceitos é mais o modo como eles fazem passar alguma coisa capaz de ampliar o nosso modo de agir e pensar do que uma aplicação justa e adequada deles.

Em relação à força, esta somente existe em relação com outra força, constituindo corpos, quer sejam biológicos, químicos, sociais, políticos ou clínicos. As forças são definidas por seu poder de afetar e serem afetadas por outras, constituindo ação sobre ação, como "incitar, induzir, ampliar, abrir, desviar, produzir, constituem afetos ativos; e ser incitado, suscitado... afetos

Guy-Debord (1931-1994) fundou a Internacional Situacionista (IS), cujas ideias abordavam a psicogeografia, a deriva e a construção de situaçōes, criticando o funcionalismo moderno presente na Arquitetura e no Urbanismo. "Os situacionistas [...] queriam provocar a revolução e pretendiam usar a arquitetura e o ambiente urbano em geral para induzir à participação, para contribuir nessa revolução da vida cotidiana contra a alienação e a passividade da sociedade" (Jacques, 2003, p. 19). 
reativos" (Deleuze, 2006, p. 79). Nessas relaçōes, o fora é uma mistura de forças, composições inéditas que desestabilizam contornos conhecidos e exigem novos modos de funcionamento. Uma relação de forças é ação sobre ação, produz realidade, também produz verdade, de modo que, para que isso aconteça, supõe um agenciamento ou um dispositivo pelo qual possa operar.

Um agenciamento é a forma positiva de uma força, sendo que as forças são imanentes ao próprio agenciamento. Nesse sentido, o acompanhamento terapêutico funciona como um dispositivo ou agenciamento, constituindo-se como um território, utilizando ou criando outros, num processo de agenciamento (agenciando ou agenciado) nessas composiçóes de força.

O agenciamento tem um polo estratificado, considerado molar, ou também chamado territorializado, com códigos específicos e funcionamento estável e reprodutor, modelando existências segundo estes códigos, restringido o campo do desejo; e outro polo, denominado máquina abstrata, molecular, descodificado ou desterritorializado que carrega novas criações em potência. Estes movimentos (territorialização, desterritorialização) coexistem no mesmo agenciamento, indo de um para o outro, num processo de reterritorialização que se faz constantemente e que:

Dá determinado termo ao devir, determinada efetuação ao acontecimento, determinado indicativo ao tempo [...], mas desterritorialização simultânea [que] libera códigos [...] carrega estados de coisas e enunciados numa linha de fuga, [...] eleva o tempo ao infinitivo, extrai um devir que já não tem termo, porque cada termo é uma parada que precisa saltar (Deleuze, 1998, p. 59).

Trata-se do acontecimento, efeito do encontro intensivo dos corpos, passagem de um estado de coisas a outro. É que o acontecimento compreende um regime intensivo de afetos e sensaçóes e revela mudanças nas relações de força, altera as linhas de força dos corpos. Afeto é a variação de potência pela qual um corpo passa quando afetado por outro nesses encontros intensivos. "Não é um sentimento pessoal, nem característica, ele é a efetuação de uma potência [...] que subleva e faz vacilar o eu" (Deleuze \& Guattari, 1997, p. 21).

Os acontecimentos, singularidades desse acompanhamento terapêutico que nos surpreenderam, fizeram hesitar e nos deslocaram de nosso lugar. Cartografamos tais elementos como linhas de composição da experiência do encontro que indicavam um potencial para mudança. Nesse sentido, abriu-se mão de uma competência ou experiência que poderia hierarquizar, categorizar ou classificar; e de uma interpretação de um mundo que seria preexistente, assim como seriam seus significados; ou mesmo uma intervenção certa, na hora certa, com a palavra certa (Passos et al., 2009). 
Com isso, a deriva e a cartografia se compõem por agenciamentos e acontecimentos; encontros marcados por acasos, mudanças e colagens de elementos que experimentamos, entre os quais, os passeios, as saídas, as ruas, as demandas do CAPS-ad, o computador, a clínica, a cidade, os conceitos, a relação entre acompanhado e acompanhante, a esquizofrenia e a saúde mental.

Desse ponto de vista, a cartografia ou a experimentação no acompanhamento terapêutico consistiu em instalar-se no território; experimentar as oportunidades que surgiam; buscar aí um lugar favorável, buscar aliados, os eventuais movimentos de desterritorialização; vivenciá-las; assegurar aqui e ali conjunções de fluxos; experimentar segmento por segmento dos contínuos de intensidade e ter sempre um pedaço de uma nova terra, um novo território (Deleuze \& Guattari, 1996).

Com os conceitos implicados e agenciados, podemos dizer que não bastaria fazer saídas para a rua, mas sim que a rua fosse um fora, "rua do fora" ou o "fora da rua", para além e aquém de qualquer rua concreta, enfim, a rua como força do fora, conjugando outras forças e, consequentemente, outra clínica. Assim, por um lado, as ruas da cidade e, por outro, a clínica se entrecruzam, ziguezagueiam, tornam-se lugares de encontros, surpresas e invençôes.

Diante dos encontros iniciais, nossa postura foi de apostar no devir da/e nas saídas, abrir-se para a deriva, cartografar, colocar de lado as certezas e incertezas, sugerindo ao acompanhado alguma coisa (ou às vezes nada). Entretanto sempre nos colocávamos à disposição. Consideramos também que aquele primeiro gesto de nos agachar inaugurou a possibilidade de que se instaurasse algo, o início de um mundo compartilhado. O encontro pediu o gesto de agachar-se, e este convocou uma presença, que poderia depois pedir palavras ou não. É a permissão desses gestos que autorizam o exercício da potência e diz a Pedro que ele é protagonista no encontro (Buenoz, 2013). A partir daí, acreditamos que se tenha inaugurado um laço de cumplicidade entre ambos. Com esses primeiros movimentos, compusemos então um território com o acompanhado.

O território é primeiramente a distância, que não é uma medida, mas um ritmo em que estamos mais ou menos distantes ou combináveis (Deleuze \& Guattari, 1997). Buscamos um território o mais flexível possível, em que o acompanhamento terapêutico deixasse de ser apenas um protocolo sob as demandas do CAPS-ad, um projeto psicoterapêutico ou apenas uma sugestão do acompanhante, mas que, de algum modo, Pedro pudesse se apropriar dos encontros como um território e assim participar da sua construção.

Retomando o conceito de deriva, podemos dizer que começamos a compor territórios a partir dos encontros que foram surgindo nas ruas, no mercado, 
nas lojas ou em casa, nas conversas, nos gestos, nas tarefas conjuntas, inclusive pelos movimentos do corpo, gestos, mudança de ritmos e um jogo de alternâncias em algumas atividades: sugerindo caminhos, lugares, deixando que ele sugerisse; levando ou deixando ele levar; conversando ou ficando em silêncio; aproximações e distanciamentos. Com as derivas, compomos o acompanhamento terapêutico, recolhendo elementos ao sabor dos encontros (Deleuze \& Guattari, 2010). Podemos dizer que o acompanhante terapêutico colocou-se junto ao acompanhado, não sabendo, aproximando-se, afastandose, dialogando, cartografando, fazendo colagens com um mundo que foi sendo construído e que transbordou para outras dimensões relacionais, fossem elas sociais, econômicas, estéticas, éticas, enfim uma (bri)colagem.

Em outra via, a deriva saiu das ruas e passou a ser feita no quarto, quando o acompanhado nos convidou para ver e "mexer" no computador que havia ganhado. Consideramos tal convite inaugural importante para nossos encontros, pois indicou uma confiança e hospitalidade com a qual Pedro nos recebia. Essa experimentação tomou-se, inicialmente, em um quarto escuro e tomado pela fumaça dos cigarros que Pedro fumava. Às vezes era necessário que se insistisse para que se abrisse a janela, pois a fumaça nos sufocava. Nessa ocasião, foi necessário que nós mudássemos a mesa do computador de lugar, uma vez que o sol que entrava batia diretamente na tela, atrapalhando a visão. Nesses encontros, com a recusa do acompanhado em fazer aulas de Informática, passamos a estar juntos, tentando ensiná-lo algumas coisas ou acompanhando as suas experimentaçóes, enquanto ele tentava explicar o que estava fazendo. Pedro se colocava a teclar e a clicar aleatoriamente nos ícones que estavam na tela até que algo fizesse algum efeito. Nesse movimento, ele começou também a fazer um uso compulsivo da máquina, trocando o dia pela noite.

Nesse processo, o computador passou a apresentar problemas técnicos e nos revezamos diante da máquina, tentando arrumar. Algumas vezes, ele pedia que nós o ajudássemos e depois ele mesmo tentava consertar. Depois foi preciso que o computador fosse levado a uma loja de manutenção. Nas primeiras vezes, ele pedia que nós o levássemos às lojas. Ele ouvia atentamente as explicaçôes do técnico, tentado entender o que era dito. Depois ele mesmo passou a levar o computador. Em uma das vezes que fomos juntos, pudemos ver que Pedro conversava e tentava se entender a seu modo com o técnico, que nos chamava para a parte do fundo da loja e explicava detalhadamente o problema. Além disso, Pedro também passou a solicitar a um sobrinho que o ajudasse com as configurações do computador.

Em algumas ocasiōes, tivemos outros encontros em que ficávamos sentados na sala em silêncio, pois o computador havia se estragado e parecia que Pedro 
se entregava a uma certa apatia. Mas insistíamos no acompanhar, à espreita, ora tensa, ora relaxada, mas nos fazendo presente. Pedro começou a prestar atenção ao movimento que eu fazia quando me mexia no sofá, mudando de posição devido ao cansaço de ficar assentado todo o tempo. Pedro então começou a perguntar coisas sobre o meu dia, do mesmo modo que eu perguntava para ele quando chegava. Ele também começou a falar de seus delírios, de como surgiram e da angústia ao começar a ouvir as vozes. Em outras vezes, ele delirava diante do computador e sobre a internet, dizendo como havia adquirido poderes em uma viagem fora do corpo e que, por esse modo, conseguia agora se livrar dos seus perseguidores e inclusive conectar-se à internet, mesmo sem o funcionamento do computador. Para isso, fazia o uso do "catar", uma composição de gestos e palavras ditas num idioma chinês antigo, segundo ele próprio nos mostrou e explicou.

Nas primeiras vezes, ficamos apreensivos e curiosos com os delírios. Pedro parecia nervoso, mas depois se acalmava. Quando disse as palavras no suposto idioma chinês, parecia que não mais voltaria a falar em português, para, logo depois, triunfante, explicar como derrotava seus perseguidores. Nessa composição que se fazia, um território, um "ciberespaço" delirante computacional se movimentava. Pedro começou também a tentar fazer coisas que ia aprendendo, como instalar programas, utilizar outros aplicativos ao seu próprio modo e a entrar em contato com pessoas diferentes, como vendedores de artigo de informática, outros vizinhos que o ajudavam, além de sair para procurar várias outras lojas de manutenção nos bairros próximos, para encontrar aquelas que oferecessem preços mais acessíveis. Nas nossas conversas, os assuntos começavam a variar entre aparentes trivialidades, o delírio e a informática, cujo vocabulário vinha sendo apropriado por Pedro. Ele começou também, antes de digitar qualquer coisa no teclado, fazer os gestos do "catar".

Nesses encontros tomados ora pela compulsão, ora pelo silêncio, ora pelos delírios, às vezes escutando, às vezes ajudando com o computador, dando explicações, tentando consertar a máquina, outras vezes apenas com uma presença discreta, acolhíamos as demandas e os silêncios de Pedro.

Essas situações, apesar do tempo cronológico, com seu início e fim, e os objetos individualizados presentes (afinal, isso é o que permite operar no mundo, reconhecê-lo e organizá-lo), eram momentos que nos tiravam de um modo operatório em relação aos objetos e, assim, nos faziam escapar. É que essa derivaesquizo também foi também tratando de tornar indefiníveis alguns contornos, algumas ideias ou planos, o que possibilitou entrar em uma relação diferente, tanto com as ruas, como com os outros elementos (computador, delírio, quarto, silêncio, etc.) com os quais propomos compor, criar, derivar e transitar por eles. 
Assim, temos a deriva também como prática estética, produzindo territórios ou mesmo desterritorializando, compondo uma clínica à deriva como processo de produção. Uma máquina de andar à deriva, ficar à deriva, máquina de derivar produzindo diferença, comunicando-se com o fora, aliando-se com o que parece estranho ou singular e, por isso, "mesmo deslocando-se [ou mesmo numa imobilidade] no espaço, é uma viagem em intensidade, em torno da máquina desejante que se erige e permanece" (Deleuze \& Guattari, 2010, p. 177).

O conceito de máquina desejante coloca em pauta o inconsciente e o desejo como processo. Esse processo maquínico, para Guattari \& Rolnik (2010), remete ao agenciamento, que não é exatamente ato (analítico), ou intervenção, mas não quer dizer que não passe por aí. Nesses termos, o processo maquínico, por meio de elementos de singularidades, pode fazer surgir outros possíveis numa situação de impasse ou paralisada: "O inconsciente se constitui exatamente no campo do possível de que este agenciamento coletivo é portador, tendo a ver com o futuro e não com o passado" (Guattari \& Rolnik, 2010, p. 281). A produção desejante se dá no instante criador; faz emergir outras coordenadas de existência, articulações funcionais, relação criadora com a situação que se estava vivendo (Guattari \& Rolnik, 2010).

É nesse sentido que, em tais experimentações no acompanhamento terapêutico, o mundo de Pedro, inicialmente fechado ou paralisado pelas recusas e isolamento, passou por zonas de intensidades segundo os raios (de sol), pessoas, passeios e objetos agenciados que o penetraram, dando lugar a outros possíveis. Se nas derivas tivemos pessoas com suas características individuadas (eu e ele), com seus papéis sociais, lugares, objetos e seus usos e as conexôes reais desses objetos e pessoas, isto é, todo um estado de coisas, havia também a velocidade ou a pressa das ruas, o acaso e o não saber nos encontros, o escuro do quarto, $o$ silêncio da sala, as surpresas e hesitações nas ruas, o terrífico ou o criativo de um delírio, um olhar atravessado, uma raiva estampada no rosto ou na fala durante o delírio, a intensidade azul do olhar de Pedro, a expressão de amizade (eis as puras qualidades ou potencialidades singulares).

O afeto é feito desses dois elementos, a qualificação de um espaço e a intensa potencialização do que nele vai ocorrer. Dois polos do afeto: potência e qualidade. "O afeto é a entidade, a potência e a qualidade [...] O afeto não existe independente de algo que o exprima, embora dele se distinga por completo" (Deleuze, 1983, p. 126). Ou seja, temos dois estados das qualidades-potências: atualizados num estado de coisas (espaço-tempo, aqui e agora, características, papéis, objetos) ou expressados por si mesmos, fora do espaço-tempo, com singularidades próprias. $\mathrm{O}$ afeto trata de extrair o rosto, ou o que o valha, por exemplo, gestos, expressões do corpo ou uma proposição, de qualquer coordenada espaço-tempo, mas pode 
também levar consigo um espaço-tempo próprio (espaço qualquer), captando mais o processo, a estação, a caminhada (Deleuze, 1983).

\section{O ESPAÇO QUALQUER}

Nessas experimentações, partindo de um espaço ou percurso determinado, por exemplo, as ruas e as demandas do serviço de saúde, com abertura para as mudanças, e para as forças do fora, vamos além das obrigações formais, limitações materiais, e o espaço então se torna indeterminado, um espaço qualquer, tal que isso não resulte em despotencialização, mas, pelo contrário, será a partir daí que algo poderá acontecer (Deleuze, 1983). Espaço qualquer é um espaço singular que perdeu sua homogeneidade, isto é, suas relaçôes e encadeamentos de suas partes. "Temos então um espaço de conjunção virtual, um puro lugar do possível [...]. A instabilidade, heterogeneidade, ausência de ligação compreendem uma riqueza de potencial ou singularidades que são condições para qualquer atualização, agenciamentos, relações de força" (Deleuze, 1983, p. 141).

É por esse espaço qualquer que se dá a implicação do desejo e nos possibilita que os elementos agenciados não se coloquem apenas como estados de coisas em suas formas, usos ou funções, mas como potencialidades; e que a montagem ou agenciamento possibilite que possam se juntar de uma infinidade de maneiras, não estando orientados uns em relação aos outros. Constituem-se, assim, as singularidades que se conjugam em um espaço qualquer (Deleuze, 1983) e possibilidades para linhas de fuga.

Em decorrência disso, pela composição de um espaço qualquer, nas derivas intensivas, fomos pegos de surpresa em movimentos que nos tomaram e nos fizeram hesitar, o que mostrou condições de mudanças nas relações de força, um acontecimento por vir, um encontro intensivo, em que "O devir é o que subtende o trajeto, como as forças intensivas subtendem as forças motrizes" (Deleuze, 1997, p. 77). Nesse contexto, as derivas são passagens da casa para a rua, das lojas para casa, do quarto para a sala, da sala para o quintal, do quintal para a mercearia; de quem acompanha para quem é acompanhado; de um delírio para uma loja; de um silêncio a uma palavra, de uma palavra para um gesto, de um conceito para outro, de um tempo para um entretempo, entre um lugar e outro, entre coisas e estados de coisas.

Essas visões diferentes constituem um conjunto de singularidades que se conjugam no espaço qualquer em que aparecem como pura potência, pura qualidade (as hecceidades são essas potências, os afetos e as intensidades). Não que a hecceidade seja um cenário ou pano de fundo; "é todo o agenciamento 
em seu conjunto individuado que é uma hecceidade, é ele que o define por uma longitude e uma latitude, velocidades e afetos, independente das formas e dos sujeitos" (Deleuze \& Guattari, 1997, p. 49).

O próprio computador, a rua, o quarto, o acompanhado, o acompanhante, a clínica, o delírio, a deriva, os conceitos que surgem, por exemplo, tornamse agenciamentos que não se separam de uma hora, de uma estação, de uma atmosfera, de um ar, de uma vida. Compõem um plano de consistência que somente tem hecceidades. As determinações espaço-tempo não são predicados das coisas, mas são dimensões de multiplicidades. Os elementos postos em jogo encontram sua individuação no agenciamento do qual eles fazem parte (Deleuze \& Guattari, 1997).

Nas derivas, com o espaço qualquer, finalidades, obstáculos, meios, subordinações, hierarquias, o que é principal ou secundário estão misturados de modo que não há meio de discerni-los; o que, por sua vez, não quer dizer que haja uma indecisão, mas uma flutuação. Por exemplo, não há o que dizer se a finalidade de se estar nas ruas, ou na casa, ou diante do computador é tal ou qual; muito menos há o que se dizer se o delírio ou o computador são obstáculos ou não; ou se ficar em casa ou sair são elementos principais ou secundários. Nesse contexto, pensamos a ação no acompanhamento terapêutico como uma ação flutuante.

\section{A AÇÃO FLUTUANTE}

Alguns autores, ao abordarem a ação no acompanhamento terapêutico, falam de ação interpretativa ou "interpret-ação". Por exemplo, Porto e Sereno (1991) afirmam que "o que prevalece é a ação [...] que conta com os recursos criativos de cada um dos envolvidos e que representa a própria saída" (p. 29). Para esses autores, a "interpretação" se faz por meio de um gesto que complementa ativamente o que está sendo feito.

Rolnik (1997) fala em fisgar elementos, farejando o aparecimento de agenciamentos virtuais, pressentir virtualidades e apontá-las. Para essa autora, as interpretações têm um sentido de exploração experimental. Articulamos então, para o acompanhamento terapêutico, uma ação experimentativa ou experimentação, marcando a ação flutuante. Essa ação flutuante possibilita sair do esquema ação-reação/sensório-motor e abrir-se a uma indeterminação, às forças do fora, possibilitando uma abertura aos afetos e também possibilitando ao acompanhado ser protagonista do acompanhamento terapêutico. 
Para exemplificar como uma ação flutuante perpassa os encontros e se compõem nas derivas, podemos dizer que, no acompanhamento terapêutico, tivemos situações rotineiras que, submetidas a um desequilíbrio entre excitação e resposta, tiravam-nos do circuito de ação-reação. Tais situações se compunham ora de uma crueza, ora beleza, ora uma leveza insuportável: uma atmosfera, às vezes, lúgubre e insalubre no quarto escuro-esfumaçado; às vezes, tragicômica pelo trânsito dos gatos que começaram a entrar pela janela do quarto; às vezes, bucólica em um passeio pela manhã ou pelo barulho de pássaros e as lembranças da roça; às vezes, urbana no perigo e tumulto do trânsito das ruas. Ocasiōes que se faziam necessárias, ou apenas nos restava ver e ouvir coisas, ou pessoas, como fazendo um inventário dos meios.

Ainda nos primeiros encontros, por exemplo, nos momentos em que andávamos aparentemente sem motivo até que o acompanhado começasse a procurar alguma coisa; ou conversando agachados na calçada; diante do uso compulsivo do computador, que parecia às vezes eterno; ou na sala de sua casa, em que o tempo parecia variar, ora passava muito rápido, ora lentamente, como a fumaça do cigarro que se alternava de um flutuar indefinido, lento, a uma passagem rápida levada por um sopro ou uma brisa forte, até o surgimento ou não de uma conversa. Nessas ocasiōes, nós nos colocávamos numa ação flutuante, sem qualquer intenção que pudesse colocar um fim ou uma resolução à determinada situação, em linhas de tempo que pareciam passar rápido demais ou que nunca chegariam. Nesse contexto, se perdia o contorno dos lugares e das funçôes; de quem acompanha e de quem é acompanhado; tempos diferentes se comunicam, nem históricos, nem eternos, mas intempestivos.

Tal tempo também se constituiu como um tempo de gestação, necessário para tentativas, construções e reconstruçôes, fracassos e acasos. "Um tempo que não é o tempo do relógio, nem do sol, nem do campanário, muito menos do computador. Um tempo sem medida, amplo, generoso" (Pelbart, 1993, p. 32), que está mais ligado a um temperar do que temporalizar, que não remete a formas ou sujeitos, mas a hecceidades que correspondem a um poder de afetar e ser afetado, afetos ativos e passivos, intensidades (Deleuze, 1998, p. 108).

Nessas situações, por mais que quiséssemos, nos esforçássemos, ou nos movêssemos, elas transbordavam para além da nossa capacidade de agir, restando apenas ver e ouvir, o que não corresponde necessariamente a uma resposta ou ação; é mais que reagir, registrar (Deleuze, 2005). Há uma impotência para agir, mas tal impotência nos capacita a ver e ouvir. "Os objetos e os meios conquistam uma realidade [...] que os fazem valer por si mesmos" (Deleuze, 2005, p. 13).

São momentos quaisquer e espaços vazios, mas não despotencializados. 
Assim, sem ações predeterminadas, as personagens parecem desaparecer e se perder em açōes que não respondem a um mecanismo sensório-motor. Temos assim as derivas compreendendo encontros em lugares e tempos que vão além e aquém do concreto e cronológico, pois levam em conta as relações de força, movimentos, linhas de territorializações e desterritorializações que se dão a partir da intensidade dos encontros e que vão compondo um cotidiano no qual se insere o acompanhamento terapêutico. É um cotidiano em sua poesia e singularidade para além-aquém de um suposto funcionalismo que a vida deva ter.

Isso não quer dizer idealizar ou ocupar o cotidiano com a clínica, nem a clínica com o cotidiano, mas ocupar a fronteira, fazer um passar pelo outro. Do mesmo modo que não é ocupar a rua com a clínica, mas fazer passar entre a rua e a clínica uma potência como uma força que compreende a vida na sua perspectiva trágica em que as dores, sofrimentos, quedas e abalos fazem parte de uma afirmação da vida em sua abundância, sem que por isso precise ser justificada ou redimida, e assim se afirma e produz diferença (Deleuze, 1976).

Dessa maneira, a deriva e a ação flutuante possibilitaram também se distanciar de uma certa psicologia moralizante e idealista, que almeja certa felicidade, a busca de virtudes morais, verdades, certezas e resoluções. Fosse em um delírio, nas ruas, no computador, no quarto ou na sala, conversando ou em silêncio, eram derivas que se compunham por espaços quaisquer e ações flutuantes, num movimento que inaugurou, em todo caso, uma transição com pontos indiscerníveis de passagem; é mais que um movimento no espaço, mais que um movimento físico, trata-se de um deslocamento no tempo, em intensidade.

\section{CONSIDERAÇÕES FINAIS}

Nesse acompanhamento terapêutico, a partir dos encontros, das surpresas, das dúvidas e hesitaçôes, fomos levados a pensar o que se passava entre acompanhado e acompanhante. Nesse sentido, cartografamos e compomos as derivas nas ruas, na casa, na sala ou quarto, no computador, pelos delírios, pelos conceitos, tempos e situações marcadas por suas intensidades.

Este artigo mostrou fragmentos dessas cartografias, dos encontros e como os conceitos funcionaram como intercessores, compondo as experimentações e fazendo passar outras possibilidades que entraram na composição de certas formas, certos territórios e seus movimentos.

Os intercessores conceituais, como cartografia, fora, força, agenciamento, acontecimento e hecceidade compuseram a deriva e possibilitaram pensar o movimento, as transformações e a criação, levando a novos modos de fazer e 
saber a clínica do acompanhamento terapêutico. Não é uma aplicação justa dos conceitos, mas uma composição pela qual é possível que passe algo e a partir da qual foi possível fazer-saber os encontros. Nessa composição, a deriva conceitual surge então como uma bricolagem desses conceitos, que ora sobrevoa, ora perpassa os encontros.

Nesse processo, pelos encontros, tivemos também as mudanças na forma de Pedro lidar com o mundo a partir de uma certa reclusão e diferenças no modo como o acompanhante articulou uma outra clínica. Pedro começou a forjar um modo de expressão, criar uma forma de cartografia que ele talvez não pudesse desenvolver na família ou numa instituição de saúde mental, e o acompanhante se tornou mais esquizo, um devir-esquizo pela desterritorialização nesses encontros.

Foram diferenças que compreenderam para ambos deixar seus territórios, aumentar o grau de abertura ao fora "que os fazem mudar de agenciamento, saltar de um agenciamento para outro" (Deleuze, 1998, p. 110). E é por esse modo que uma clínica também foi forjada como uma clínica dos encontros que não são entre um indivíduo e outro, mas são encontros de partes expressivas nos planos de corpos, lugares, das palavras, gestos, ritmos e sons, isto é, hecceidade em vez de subjetividade. Em vez de ser coisa ou pessoa, a hecceidade é, contrariamente, acontecimento.

Acontecimentos tomados em um espaço e o tempo extensivo que nos serviu de referência ao mesmo tempo em que tivemos intensidades que arrastaram um termo e outro do encontros, nos quais o desejo se relaciona com a produção de modos de existência, não tem por objeto pessoas ou coisas, mas uma maneira de ser, forma de se relacionar, é todo um agenciamento de coisas (seja uma rua, uma paisagem ou um indivíduo) e suas relações de movimento e intensidades; tratase de um processo de produção que compõe um indivíduo, que o decompõe ou modifica, corresponde a intensidades que o afetam, aumentando ou diminuindo sua potência de agir.

Nos encontros intensivos, o que se passou entre acompanhado e acompanhante foi um fluxo incessante, um devir que arrastou tudo em derivas e novos modos de pensar e agir. Essa é a arte cartográfica com suas posiçôes, trajetos e caminhos, passagens e movimentos e ritmos. São trajetos comuns, mas o devir faz do trajeto, seja ele qual for, uma viagem (Deleuze, 1997). 


\section{REFERÊNCIAS}

Araújo, F. (2006). Um passeio esquizo pelo acompanhamento terapêutico: dos especialismos à política de amizade. Niterói: Do Autor.

Buenoz, P. (2013, 18 de março). Expressão artística e o universo da imaginação na infância. Reuniōes Abertas do GECLIPS. Uberlândia: Universidade Federal de Uberlândia.

Deleuze, G. (1983). Cinema 1: a imagem-movimento. (S. Senra, Trad.). São Paulo: Brasiliense.

Deleuze, G. (1976). Nietzsche e a filosofia. (R. J. Dias \& E. F. Dias, Trads.). Rio de Janeiro: Rio.

Deleuze, G. (1997). Crítica e clínica. (P. P. Pelbart, Trad.). São Paulo: Ed. 34.

Deleuze, G. (1998). Diálogos/Gilles Deleuze, Claire Parnet. (E. A. Ribeiro, Trad.). São Paulo: Escuta.

Deleuze, G. (2005). Cinema 2: a Imagem-tempo (E. A. Ribeiro, Trad.). São Paulo: Brasiliense.

Deleuze, G. (2006). Foucault. (C. S. Martins, Trad.), (R. Ribeiro, Rev.). São Paulo: Brasiliense.

Deleuze, G. (2010). Conversaçôes. (P. P. Pelbart, Trad.). São Paulo: Ed. 34.

Deleuze, G. \& Guattari, F. (1995). Mil platôs: capitalismo e esquizofrenia. (A. G. Neto e C. P. Costa (Trads., Vol. 1). São Paulo: Ed. 34.

Deleuze, G. \& Guattari, F. (1996). Mil platôs: capitalismo e esquizofrenia. (T. A. G. Neto, A. L. Oliveira, L. C. Leão \& S. Rolnik, Trads., Vol. 3). São Paulo: Ed. 34.

Deleuze, G. \& Guattari, F. (1997). Mil platôs: capitalismo e esquizofrenia. (S. Rolnik, Trad. (Vol. 4). São Paulo: Ed. 34.

Deleuze, G. \& Guattari, F. (2010). O anti-Édipo: capitalismo e esquizofrenia 1. (L. B. L. Orlandi, Trad.). São Paulo: Ed. 34.

Guattari, F. \& Rolnik, S. (2010). Micropolitica: cartografias do desejo. (10a ed.). Petrópolis: Vozes. 
Jacques, P. B. (2003). Circulação de ideias situacionistas no campo do Urbanismo. In: P. B. Jaques (Org.), Apologia da deriva: escritos situacionistas sobre a cidade. (pp. 25-30). Rio de Janeiro: Casa da Palavra.

Pelbart, P. P. (1993). A nau do tempo-rei: sete ensaios sobre o tempo da loucura. Rio de Janeiro: Imago.

Passos, E., Kastrup, V. \& Escóssia, L. (Orgs.). (2009). Pistas do método da cartografia: pesquisa-intervenção e produção de subjetividade. Porto Alegre: Sulina.

Porto, M. \& Sereno, D. (1991). Introdução à clínica do acompanhamento terapêutico. In: Equipe de Acompanhantes Terapêuticos do Hospital-Dia A Casa (Orgs.), A rua como espaço clínico: acompanhamento terapêutico. (pp. 1740). São Paulo: Escuta.

Rolnik, S. (1997). Clínica nômade. In: Equipe de Acompanhantes Terapêuticos do Instituto A Casa (Orgs.), Crise e cidade: acompanhamento terapêutico. (pp. 83-97). São Paulo, SP: EDUC. 